\title{
The Effect of Direct Instruction Strategy on Math Achievement of Primary 4th and 5th Grade Students with Learning Difficulties
}

\author{
Ahmad Abdulhameed Aufan Al-Makahleh \\ Full time Lecturer, Department of Special Education \\ Princess Rahma College, Al-Balqa Applied University, Jordan \\ E-mail: ahmed_makahleh@yahoo.com
}

$\begin{array}{lc}\text { Received: March 30, } 2011 \quad \text { Accepted: April 21, } 2011 \quad \text { Published: November 1, } 2011 \\ \text { doi:10.5539/ies.v4n4p199 } & \text { URL: http://dx.doi.org/10.5539/ies.v4n4p199 }\end{array}$

\begin{abstract}
This study seeks to verify the effect of direct instruction strategy on Math achievment of students with learning difficulties in the fourth and fifth grade levels and measure the improvement in their attitudes to Mathematics.

Sample consisted of sixty (60) students with Math learning difficulties attending 4th and 5th grade level resource rooms recruited from six School Districts within the metropolitan Directorate of Education. Participants were randomly assigned to control $(\mathrm{N}=30)$ and experimental $(\mathrm{N}=30)$ groups. Experimental students received training on basic Math skills using the Direct Instruction Strategy, whereas the control groups students were taght traditionally.

Achievement test were built to measure basic mathematical skill among fourth and fifth grade students as a pre-test and post-test and validity and reliability coefficients were secured. To measure student attitudes to mathematics, attitudes to mathematics scale was developed and tested for validity and reliability.
\end{abstract}

The achievement test was administered as pre-test and post-test, Results from the statistical analysis indicated a perceived effect of the direct instruction strategy on basic skills achievement of fourth and fifth grade students with learning difficulties and improved their attitudes to mathematics.

To identify basic skills achievement level of fourth and fifth grade students.

Keywords: Mathematics Learning Difficulty, Direct Instruction Strategy

\section{Introduction}

As a field of research, learning difficulties witnessed rapid developments and far-reaching in the interpreting theorization of such disability, which yielded many instructional strategies aiming at improving academic achievement of students with learning disabilities. In practice, traditional instructional strategies were unable to solve problems related to learning of mathematics by learning difficulties students since they typically have given little attention to problems experienced by this population which require instructional strategies that respond to the needs of such students (Dettori \& Ott, 2006; Dowker, 2005).

The literature review of studies conducted on teaching strategies of students with learning difficulties reveals that they predominantly focused on language, reading and writing issues, while little concern was given to mathematics (Osmon et al., 2006; Kinder et al., 2005). Some authors were greatly concerned with mathematics learning difficulties and their studies, in general, sought to develop remedial strategies basically for students having problems related to attention, memory, perception, and motivation, have ineffective skills in the computational operations, mathematical inference, mathematical concepts and other problems related to executive strategies all of which contribute to their low achievement (Al-Rousan et al., 2004; Geary, 2006; Barnes et al., 2006).

Many reports have been released by the National Association of Math Teachers emphasizing on the need to provide assistance to students with mathematics learning difficulties in mastery of the basic mathematical skills through a number of teaching methods and strategies that would make it easier for learners to understand general mathematical formulas, increase retention, and improve performance in mathematics by understanding the relationship between concepts and numbers (Bryant, 2005; Ginsburg, 1997).

Behavioral psychology is one of the disciplines that that provide meaningful theorization to explain learning disabilities, cast light on the nature of problems encountered by learners, provide basis on which to diagnose, evaluate and treat mathematics learning difficulties and suggest appropriate teaching methods. In this context, many 
approaches have been taken in teaching students with learning difficulties, including direct instruction, explicit learning, and task analysis, where teachers take a frank position regarding what definite skills they should teach, and move step-by-step with learners when they teach them a definite skill rather than leave them to their own experience. This approach provides students with problem solving models, offers the support they need and allow them the opportunity to practice what they have learned over different learning stages (Lerner, 2000; Mercer, 2003).

\section{Direct Instruction}

As an instruction strategy, Direct Instruction typically focuses on accomplishing instructional targets by providing training on skills that are closely related to the targets. Further, it requires well-planned, neat, and organized lessons. Training provided usually revolves around small modules where teacher directs the instructional process depending on the skills acquired, providing a set of procedures that fit with instructional targets and arrange the environment accordingly. The main goal of this strategy is to reach with students to the mastery level before learning a new skill (Adams \& Engelmann, 1996; Kinder et al, 2005).

The direct instruction was first used by Engelmann (1960) as a systematic instructional strategy based on a set of bases (Edward, 1994; Adams \& Engelmann, 1996).

The literature review showed that this instructional model had developed as a result of many thoughts and arguments that together formed the rationale of the so-called Direct Instruction strategy. The arguments covered three fields: skills and system analysis, social behavioral modeling, and teacher-centered research studies. High level skills are analyzed to component part, and training will provided sequentially until reaching the mastery level practicing an intricate skill (Marzano \& Pollock, 2001).

The Direct Instruction strategy relies on the behavioral approach in which instructions are given explicitly and sequentially when a skill is to be learned, or instructional models are presented without any distractions. This strategy is focused on procedures followed by teachers and the curriculum and identify specifically and explicitly what skills need to be learned step-by-step, instead of leaving students to their own experience. This, of course, improves and accelerates learning in students (Adams \& Engelmann, 1996; Kinder et al, 2005).

The Direct Instruction strategy involves the following steps:-

i. Measuring student performance directly and accurately pre-teaching while concentrating on basic concepts much demanded by a student.

ii. Goals are set accurately, operationally formulated so that to introduce the final behavior expected from the student.

iii. Analyze the instructional task and arrange elements sequentially and systematically.

iv. Allocate sufficient time for task learning

v. Providing feedback regarding student performance

vi. Instruct student to practice the task that he masters more through clear instructions.

vii. Display student performance in suitable graphical forms.

viii. Providing students with appropriate problem solving forms, supporting students on their learning, providing practices that match specific skills. This strategy is viewed as appropriate for different academic disciplines including mathematics (Adams \& Engelmann, 1996; Wesly Gersten, 2001; and Halhan et al., 2007).

\section{Statement of the Problem}

Perceivably, students with mathematics learning difficulties have increased in number and special education strategies are therefore required. Hence, special educators developed instructional strategies in an attempt to solve problems faced by students with math learning difficulties, since the curriculum lacks necessary training, practice, and multiple examples, which formed a real challenge for educators working with students with math learning difficulties.

In Jordan, many educational conferences were held that called for learning individuation in that individual students learn based on one's aptitudes and capabilities using different strategies in order to cope with the recently perceived problem of low math achievement among elementary school students (First Educational Conference, 1985).

To improve math achievement among students with math learning difficulties, there has been greater awareness to this field in recent years. Because of the lack of related studies that addressed math remedial strategies in Jordan, this author addresses this issue for purpose of helping students with learning difficulties in the first three classes to improve 
their mathematics achievement. However, this study is among the first studies in Jordan that use the direct instruction strategy to overcome mathematical difficulties faced by students.

\section{Significance of the Study}

The importance of the present study stems from the following:

i. Identify the effect of direct instruction strategy on mathematics achievement of fourth and fifth students with learning difficulties.

ii. Implementation of curriculum sequentially and move from one skill mastered to the other step-by-step.

iii. Identification attitudes of fourth and fifth grade students after application of the direct instruction strategy.

\section{Study Objectives}

i. Examination of the effect of direct instruction strategy on the improvement of mathematics achievement and attitudes among fourth and fifth grade students with learning difficulties.

ii. Suggesting a model of student progress with a skill that provides feedback for both student and teacher.

\section{Study Questions}

i. Are there statistically significant differences among mean grades of students with learning difficulties on mathematics post test attributed to the teaching strategy?

ii. Are there statistically significant differences among mean grades of student performance on the post test attitudes scale attributed to the teaching strategy?

\section{Sample}

Participants $(\mathrm{N}=60)$ were fourth and fifth students with mathematics learning difficulties attending the resource room recruited from the Education Directorate of Capital Amman, Amman First and Second Directorates of Education, and Private Education Directorate of Education. Sample was randomly selected from schools with learning centers from the three Directorates of Education.

\section{Procedures}

The present study follows the experimental methodology in which schools were randomly selected and participants were randomly assigned to experimental and control groups to identify effect of the independent variable on the dependent variable.

\section{Instrumentation}

Achievement Test-Content analysis of fourth and fifth mathematics textbooks and screening facts, concepts, and the four mathematical operations (strategies) (addition, subtraction, multiplication and division) resulted in developing 80 -item mathematics achievement test measuring mathematics achievement level of fourth and fifth students with learning difficulties.

i. Attitudes to Mathematics Scale-twenty items scale developed by the author measured firth and fifth student attitudes mathematics over three aspects: student attitudes to mathematical content, student attitudes to mathematics classroom, and student attitudes to using mathematical skills in day-to-day life.

\section{Prior Studies}

\section{i. Kinder et. al, (2005)}

This study was a meta-analysis of most studies that investigated direct instruction strategy to teach students with special needs. This study reviewed 37 studies conducted with reading, language, writing, spelling, and mathematics learning difficulties. Only one study concerned with direct instruction strategy of mathematics. This study analyzed the studies reviewed in terms of title, objective, questions, summary and subjects. Data analysis revealed results that confirmed that direct instruction strategy proved successful in teaching reading, spelling, writing, language, or computation to students with special needs irrespective of grade level or age. Results also reported perceived improvement in performance on different academic fields. Results indicated that direct instruction and special education have the power to control academic progress of students with special needs. In addition, effective design of the direct instruction strategy complies with IDEA criteria especially students with learning difficulties. Results stressed that the interest in mathematics achievement in the public and special education is somewhat new and more studies in this field still needed.

\section{ii. Mackenzie et. al, (2004)}

Sought to investigate the effectiveness of direct instruction strategy in linking kindergarten mathematical concepts. Sample consisted of sixteen students five of whom experienced developmental retardness aging 4-5 years old. 
Participants were pre-test and post-test were administered to participants to verify the training effect, which lasted 5-6 weeks for 10-20 minutes a day. Thirty sequenced and definite lessons were applied. Results demonstrated that developmentally retarded students showed improved on the developmental battery, better performance on the mathematical concepts test, and that children were ready at the entry-level to mathematics.

\section{iii. Edward L. (1994)}

This longitudinal study lasted six years supported the effectiveness of direct instruction strategy when used in sequenced, definite and organized way synchronized with the feedback and direct reinforcement of correct responses regarding basic mathematical, reading and language skills. Participants were students with learning difficulties in the elementary third grade level from Valentine Schools-California. Prior to administration of the direct instruction strategy, pre-test results indicated mean achievements in reading (32\%), mathematics (42\%), and language (35\%). Following application of the direct instruction strategy, results revealed higher mean achievements of reading (58\%), mathematics $(73 \%)$, and language $(70 \%)$. The raise in performance is accounted for by the direct instruction strategy that improved basic skills and perceivably increased achievement, in general.

\section{iv. Sawalha (2004)}

This study was conducted in Jordan for purpose of inquiry the effect of the direct instruction strategy on learning mathematical skills by resource room students with mathematics learning difficulties by using a suggested program to improve achievement, academic self-concepts, and student attitudes to mathematics. Participants were sixty students. Results showed perceived effectiveness of the direct instruction strategy in improving mathematics achievement by students with learning difficulties, their attitudes and self-concept among the experimental subjects. In addition, retention of learning was better in experimental group who exposed to direct instruction strategy that lasted even after the study completed.

\section{v. Kaufmannl and Thony (2003)}

The purpose of this study was to identify effect of direct instruction strategy through a mathematical intervention program that principally focused on the basic conceptual and cognitive numerical skills in mathematics, and to investigate whether the early intervention program helps students with learning difficulty. Participants were six children with mathematics learning difficulties who received training individually or in small groups for one semester. To practice on skills, the direct instruction strategy was applied. Results revealed that the early interventions with the direct instruction strategy yielded perceived learning of numerical and conceptual facts; all experimental students partially or wholly performed the tests, and the training received resulted in mastery of all computational operations.

\section{vi. Wesley, \& Gresten, (2001)}

The purpose of this study was to identify effect of direct instruction strategy on fifth and sixth grade students' achievement after three years of related training and follow up of impacts on low achievers. The follow up was conducted through an evaluation of the effect of direct instruction strategy using five different methods: two mathematics achievement tests, large-scale achievement test, and Metropolitan test. Performance of both groups was compared and contrasted. Results indicated constant and strong effect of the direct instruction strategy on spelling and reading skills, whereas moderate effect was noticed on other academic subjects such as mathematics and writing. In addition, student's performance was high on facts recalled, problem solving, and mastery of basic skills. Further, students who ceased the program achieved below compared with those continued with the program.

\section{vii. Manalo et.al, (2000)}

This study compared three instructional methods: direct hints to memory (following a set of steps), direct instruction, and no-direct instruction on mathematical basic skills. Ninety-nine $(F=23, M=6)$ students with mathematics learning difficulties participated in the study. Participants were assigned to four groups: group one was taught using direct hints to memory; group two received varied direct instructions, group three exposed to direct instruction strategy, where each skill was taught definitely and clearly. However, group four was taught traditionally without using direct instructions. Results showed that students who exposed to training with direct hints to memory or taught using the direct instruction strategy achieved mathematical skills better than the traditionally trained group.

\section{viii. Din. (1998)}

This study aimed at investigating effect of the direct instruction strategy on learning and mastery of basic mathematical skills by students with learning difficulties and measuring the effect on their achievement. Participants were 19-students with learning difficulties $(M=10, F=9)$, age ranged between 7-16 years attending primary and middle classes. Students were exposed to a program teaches mathematical basis skills using the direct instruction strategy. Student learned numerical concepts, basic operation of addition, subtraction, multiplication tables, using 
mathematical skills in finding solution to verbalized problems. The program was applied individually for five months. Findings revealed that students with learning difficulties who exposed to the program using the direct instruction strategy were better in the mathematical basic skills.

\section{ix. Seman. (1996)}

Sought to identify the effect of using direct instruction strategy, feedback, and mistake correct by teacher on student with learning difficulties compared with normal students. The study procedures were applied and participants both normal and with learning difficulties were taught academic skills in mathematics and other subjects using the direct instruction strategy. The tests administered measured how accurate were their verbal and written responses to the skills they learned. Results supported effectiveness of the direct instruction strategy in teaching different academic skills to students in general whether normal or with learning difficulties.

\section{Results and Discussion}

First: Are there statistically significant differences among mean scores of students with learning difficulties on the mathematics post-test attributed to teaching method?

Results from the present study demonstrate statisitcally sfignificnat differences among mean scores of the experimental group members on the pre-test and post-test as shown by table 1 .

Table 1 shows differences among mean scores of the experimental group members (exposed to the direct instruction strategy) on the pre-test ( $M=16.80)$ versus the post-test $(\mathrm{M}=40.73)$.

In addition, the table shows differences among mean scores of the control group members (exposed to traditional teaching method) on the pre-test $(M=15.93)$ versus the post-test $(M=22.70)$.

To identify whether there were differences among mean scores of the experimental and control group on the mathematics achievement post-test, ANCOVA test was conducted to explore the effect of using the direct instruction strategy on mathematics achievement of students with learning difficulties after controlling effect of pre-test during the experimental treatment as shown by table 2 .

Table 2 indicate statistically significant differences $(F=120.51, \alpha<0.05)$ among achievements of the experimental and control subjects on mathematics post-test. In addition, as shown in the table, experimental subjects scored higher $(\mathrm{M}=36.33)$ than the control subjects $(\mathrm{M}=18.30)$. The result that the experimental group members scored higher compared with the control group members implies that the direct instruction strategy effectively improved achievements of students with learning difficulties.

This result agrees with results from many studies (Kinder, et. 2005; Mackenzie, 2004; Edward, 2004; Din, 1998; Seman, 1996; Sawalha, 2004) that confirmed the effectiveness of direct instruction strategy compared with traditional method on the improved mathematics achievement of students with learning difficulties and increasing their mastery of basic skills.

\section{Results Relaed to the Second Question}

Are there statistically significant differences at $(\alpha<0.05)$ among mean scores of students on the attitudes to mathematics scale attributed to the teaching method?

To answer this question, means and standard deviations of scores obtained by participants on the attitudes scale pre-test and post-test as table 3 shows.

Table 3 shows mean scores of the experimental group members who exposed to the direct instruction strategy on the attitudes pretest $(M=1973)$ versus $(M=34.47)$ on the post-test. In addition, the table demonstrates mean scores of the control group members who were taught traditionally on the attitudes pre-test $(M=19.97)$ versus $(M=22.77)$ on the post-test.

To identify whether such differences were statistically significant, co-variance analysis test (ANCOVA) was conducted to explore the effect direct instruction strategy has on attitudes to mathematics among students with learning difficulties, and to control for the effect of the attitudes pre- test in the experimental treatment as shown by table 4.

Table 4 indicates statistical significant differences $(\mathrm{F}=95.13)$ among participant performances on attitudes to mathematics posttest, which is statistically significant at $(\alpha<0.05)$. Results demonstrate that mean scores were higher $(M=31.07)$ for experimental than for control $(M=18.37)$ group members. The implication of the result that experimental group members had higher mean scores compared with the control group is that the direct instruction strategy effectively improved attitudes of students with learning difficulty to mathematics. 
This result receives support from many studies (Kinder, et. 2005; Mackenzie, M. 2004; Edward L, 2004; Seman, 1996; and Sawalha, 2004), which confirmed the effect of a sequence, definite, and well-organized training strategy on attitudes to mathematics and mathematics class among students with learning difficulties.

\section{References}

Adams, G., \& Engelmann, S. (1996). Research on Direct Instruction: 25 Years Beyond DISTAR Seattle, WA: Educational Achievement Systems.

Al-Rousan, Farouq, Al-Khateeb, Jamal, \& Al-Natour, Mayada. (2004). Learning Difficulties. Arabic Open University.

Barnes, M., Wilkinson. M., Khemani, E., Boudesquie. A., Dennis, M., \& Fletcher, J. (2006). Arithmetic Processing in Children with Spina Bifida. Journal of Learning Disabilities. Vol.39, No 2, 174-187

Bryant, Diane. (2005). Commentary on Early Identification and Intervention For Student With Mathematics Difficulties. Journal of Learning Disabilities. 38 (4), 340-345

Dettori, Giuliana, \& Ott, Michela. (2006). Looking Beyond the Performance of Grave Underachievers in Mathematics. Internevtion in Scool And Clinic. Vol.41, No 4, 201-208

Din, Fengs. (1998). Use Direct Instruction to Quickly Improve Reading Skills. ERIC Document Reroduction Service NO. ED 416467.

Dowker, Ann. (2005). Early Identification and Intervention for Students With Mathematics Difficulties. Journal of Learning Disabilities. Vol. 38, No 4, 324-332

Edward, L. Anderson. (1994). Education That Work, The Child is Always Right, Part Five. Direct Instruction This paper is based upon a talk that Dr.Anderson gave on August 2, 1994, sponsored by the Chautauqua Institution, Chautauqua, New York.

First Arabic Conference held at Amman Training College (from 31/08-02/09/1985). UNRWA. Education Department.

Geary, C. David. ( 2006). Dyscalculia at an Early Ege; Characteristics and Potential Influence on socio-Emotional Development. Encyclopedia on Early Childhood Development, Learning Disabilities, published on March 15- 2006 Center of Excelence For Early Childhood Development. Ginsburg. H (1997). Mathematics Learning Disabilities:Aview from Developmental Psychology. Journal of Learning disabilities. 30 (1), 20-34

Halahan, Daniel, Lloyd, John, Kaufman, James, \& Weiss, Margaret/Translated by Adel Mohammad. (2007). Learning Difficulties: Concept, Nature, Therapeutic Learning, First Ed., Amman, Jordan. Dat Al Fekr.

Kaufmannl, P., \& Thony, B. (2003). Evaluation of a numeracy intervention program focusing on basic numerical knowledge and conceptual knowledge: apilot study. Journal of Learning Disability. 36, 564-573. http://dx.doi.org/10.1177/00222194030360060701

Kinder. D., Kubina, R., \& Marchand-martella, N. (2005). Special Education and Direct Instruction: An Effective Combination. Journal of Direct Instruction, 5 (1), 1-36

Lerner, Janet. (2000). Learning Disabilities Theories Diagnosis And Teaching Strategies. USA Houghton Mifflin Company.8th edition.

Mackenzie, A., Marchand, R., Martella, E., Moore, M., \& Mantella, RC. (2004). Teaching Basic Math Skills to PreSchool Using Connecting Math Concepts Level K. Journal of Direct Instruction. 4, 85-94

Manalo, E., Bunnell, K., \& Stillman, A. (2000). The use of process mnemonics strategies in teaching students with math learning disabilities Learning Disabilities Quarterly. 23, 137-166. http://dx.doi.org/10.2307/1511142

Marzano, R., Pickering, D., \& Pollock, J. (2001). Classroom Instruction That Works. Research Based Strategies for Increasing Student Achievement, (2nded). USA: A SCD, McREL.

Mercer, C., \& Mercer, Nr. (2003). Teaching Students with Learning Problems. 7th edition, New Jersey.

Osmon, D., Smerz, J., Braun, M., \& Plambeck, E. (2006). Processing Abilities Associated with math skills in Adult learning Disability. Journal of Clinical and Experimental Neuropsychology. 28, 84-95. http://dx.doi.org/10.1080/13803390490918129

Sawalha, Auniya. (2004). The Role of Direct Instruction Strategy on Education of some Mathematical Skills to Students with Learning Difficulties. Learning Difficulties Review. Issue (5), 41-47 
Seman, M. (1996). The Effect of Direct Instruction of Teacher Effectiveness and Student Performance in Integrated Math Elementary Math Classes. D.A.I. 56 (8), 3082

Wesley, C., \& Gersten, R. (2001). Follow-up of Follow Through: The Later Effects of the Direct Instruction Model on Children in Fifth and Sixth Grades. Journal of Direct Instruction. 3 (2), Winter.

Table 1. Means and Standard Deviations of Participant Scores on the Achievement Test

\begin{tabular}{|c|c|c|c|c|}
\hline \multirow{2}{*}{ Group } & \multicolumn{2}{|c|}{ Pre-test } & \multicolumn{2}{c|}{ Post-test } \\
\cline { 2 - 5 } & $M$ & $S D$ & $M$ & $S D$ \\
\hline Experimental & 16.8 & 6.24 & 40.73 & 8.55 \\
\hline Control & 15.93 & 6.01 & 22.70 & 7.89 \\
\hline
\end{tabular}

Table 2. Co-variance analysis of differences among experimental and control groups members on the achievement test

\begin{tabular}{|c|c|c|c|c|c|}
\hline Source of Variance & Total Squares & Freedom Degrees & Mean Squares & $($ F) & $\boldsymbol{\alpha}$ \\
\hline Pre-test & 1880.55 & 1 & 1880.55 & 52.43 & 0.00 \\
\hline Groups & 4322.49 & 1 & 4322.49 & 120.50 & 0.00 \\
\hline Error & 2044.41 & 57 & 35.87 & & \\
\hline Total & 8247.46 & 59 & & & \\
\hline
\end{tabular}

Table 3. Means and Standard Deviations of Experimental and Control Subjects on the Attitudes Scale

\begin{tabular}{|c|c|c|c|c|}
\hline \multirow{2}{*}{ Group } & \multicolumn{2}{|c|}{ Pre-test } & \multicolumn{2}{c|}{ Post-test } \\
\cline { 2 - 5 } & $M$ & $S D$ & $M$ & $S D$ \\
\hline Experimental & 19.73 & 5.81 & 34.47 & 6.76 \\
\hline Control & 19.97 & 5.46 & 22.77 & 5.73 \\
\hline
\end{tabular}

Table 4. ANCOVA test results regarding scores variance between the experimental and control groups on the attitudes scale

\begin{tabular}{|c|c|c|c|c|c|}
\hline Source of Variance & Total squares & Freedom Degrees & Mean Squares & (F) & $\boldsymbol{\alpha}$ \\
\hline Pre-test & 766.96 & 1 & 766.96 & 28.92 & 0.00 \\
\hline Groups & 2523.12 & 1 & 2523.12 & 95.13 & 0.00 \\
\hline Error & 1511.88 & 57 & 26.52 & & \\
\hline Total & 4801.95 & 59 & & & \\
\hline
\end{tabular}

